\title{
Accelerating the Delivery of Home Performance Upgrades through a Synergistic Business Model
}

Tom Schirber and Cindy Ojczyk NorthernSTAR Building America Partnership 


\section{NOTICE}

This report was prepared as an account of work sponsored by an agency of the United States government. Neither the United States government nor any agency thereof, nor any of their employees, subcontractors, or affiliated partners makes any warranty, express or implied, or assumes any legal liability or responsibility for the accuracy, completeness, or usefulness of any information, apparatus, product, or process disclosed, or represents that its use would not infringe privately owned rights. Reference herein to any specific commercial product, process, or service by trade name, trademark, manufacturer, or otherwise does not necessarily constitute or imply its endorsement, recommendation, or favoring by the United States government or any agency thereof. The views and opinions of authors expressed herein do not necessarily state or reflect those of the United States government or any agency thereof.

Available electronically at SciTech Connect http:/www.osti.gov/scitech

Available for a processing fee to U.S. Department of Energy and its contractors, in paper, from:

U.S. Department of Energy

Office of Scientific and Technical Information

P.O. Box 62

Oak Ridge, TN 37831-0062

OSTI http://www.osti.gov

Phone: 865.576 .8401

Fax: 865.576.5728

Email: reports@osti.gov

Available for sale to the public, in paper, from:

U.S. Department of Commerce

National Technical Information Service

5301 Shawnee Road

Alexandria, VA 22312

NTIS http://www.ntis.gov

Phone: 800.553 .6847 or 703.605 .6000

Fax: 703.605.6900

Email: orders@ntis.gov 


\title{
Accelerating the Delivery of Home Performance Upgrades through a Synergistic Business Model
}

\author{
Prepared for: \\ The National Renewable Energy Laboratory \\ On behalf of the U.S. Department of Energy's Building America Program \\ Office of Energy Efficiency and Renewable Energy \\ 15013 Denver West Parkway \\ Golden, CO 80401 \\ NREL Contract No. DE-AC36-08GO28308 \\ Prepared by: \\ Tom Schirber and Cindy Ojczyk \\ NorthernSTAR Building America Partnership \\ University of Minnesota \\ 2004 Folwell Avenue \\ St. Paul, MN 55108 \\ NREL Technical Monitor: Stacey Rothgeb \\ Prepared under Subcontract No. KNDJ-0-40338-04
}

April 2016 
The work presented in this report does not represent performance of any product relative to regulated minimum efficiency requirements.

The laboratory and/or field sites used for this work are not certified rating test facilities. The conditions and methods under which products were characterized for this work differ from standard rating conditions, as described.

Because the methods and conditions differ, the reported results are not comparable to rated product performance and should only be used to estimate performance under the measured conditions. 


\section{Contents}

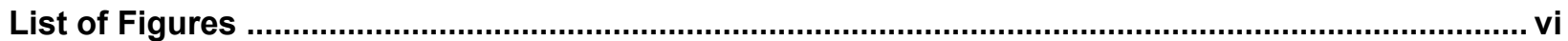

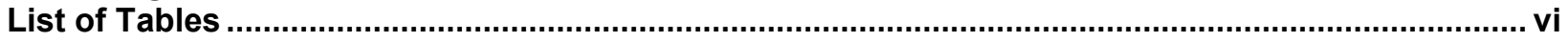

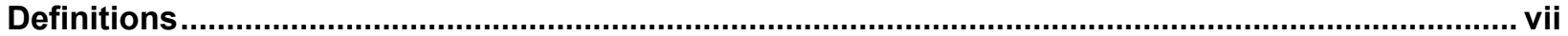

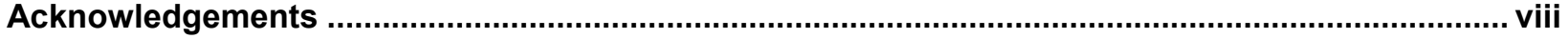

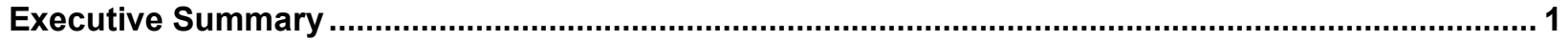

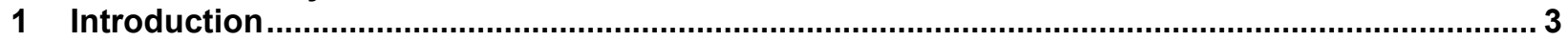

2 Background: Homeowners Resist Installing Energy Upgrades .............................................. 4

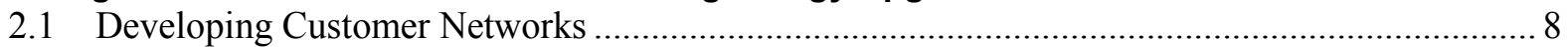

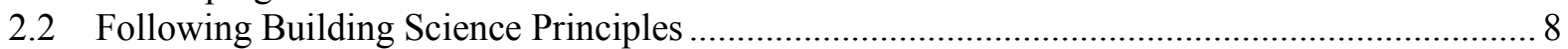

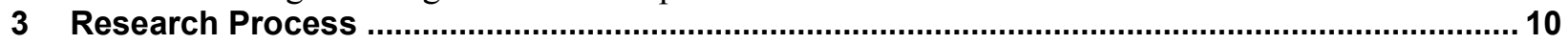

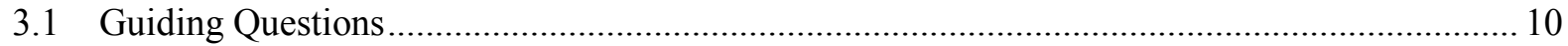

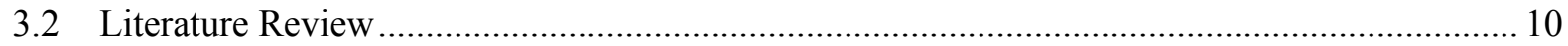

3.3 Interviews with Key Personnel from Home Service Companies .............................................. 11

3.4 Questionnaire for Home Performance Professionals ............................................................ 11

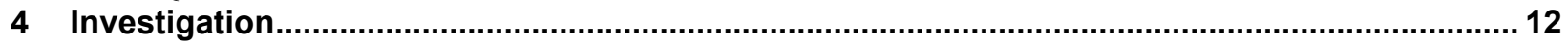

4.1 Home Service Providers Show Success in Marketing to Homeowners ...................................... 12

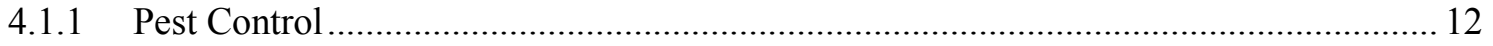

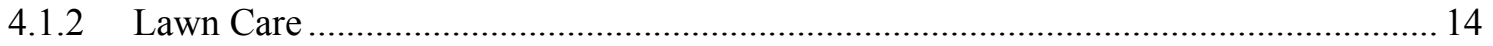

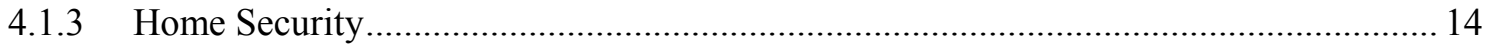

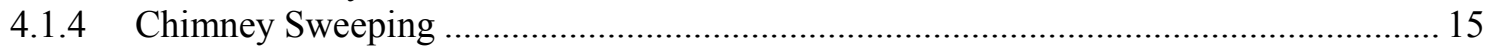

4.2 Interviews with Key Personnel from Home Service Companies ............................................. 15

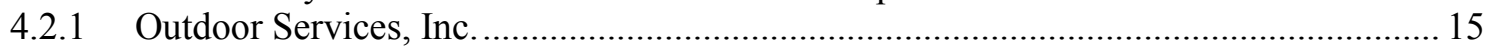

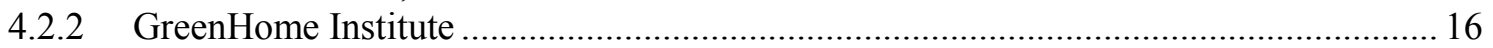

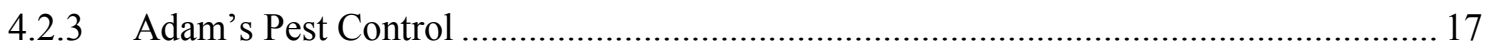

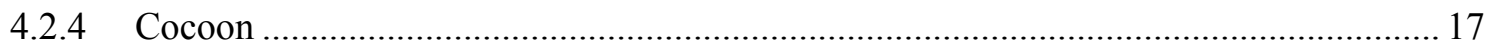

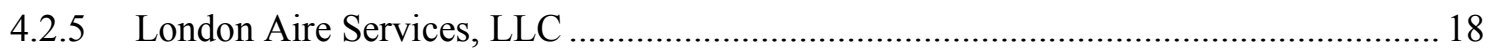

4.2.6 HUB Energy Group, LLC …………...................................................... 18

4.3 Questionnaire for Home Performance Professionals ................................................................. 23

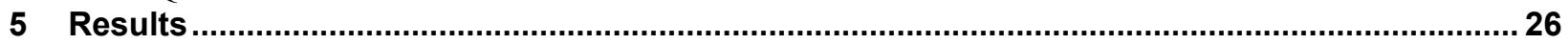

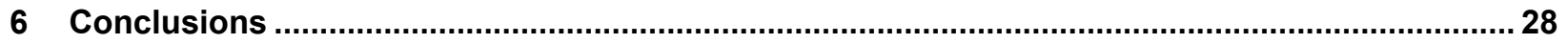

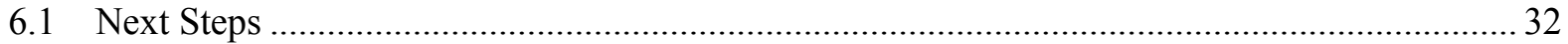

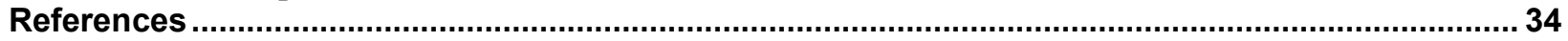

Appendix A: Online Questionnaire for Minnesota Building Performance Association Members.... 37 


\section{List of Figures}

Figure 1. Order of remodeling activities to reduce risk (Huelman 2014) ............................................. 7

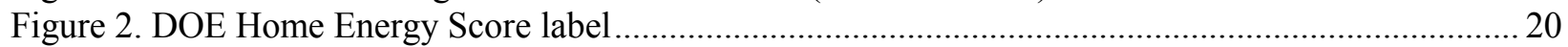

Figure 3. Graphic supplied by HUB Energy Group showing business connections to the HUB .............. 22

Figure 4. Types of building science work performed by MBPA members .......................................... 23

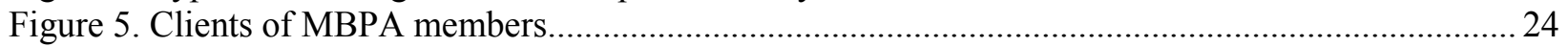

Figure 6. Member interest in working with nationally-based home service companies........................... 24

Figure 7. Member interest in working with locally-based home service companies............................... 25

\section{List of Tables}

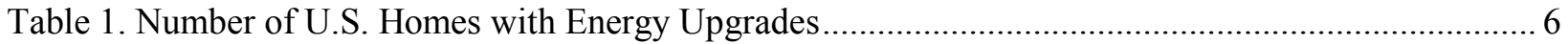




\section{Definitions}

BA

DOE

GHI

HVAC

MBPA
Building America Program

U.S. Department of Energy

GreenHome Institute

Heating, ventilating, and air conditioning

Minnesota Building Performance Association 


\section{Acknowledgements}

This report was prepared for the U.S. Department of Energy Building America Program. Funding for this work was provided by the National Renewable Energy Laboratory under contract KNDJ-0-40338-05. The primary authors were Tom Schirber from the University of Minnesota and Cindy Ojczyk from Simply Green Design. The authors would like to acknowledge the contributions and support of Pat Huelman from the University of Minnesota for providing expertise and serving as an advisor to the project and Tom Schirber from the University of Minnesota for coordinating and editing the report.

We also thank representatives from the following businesses for participating in interviews for this report:

- Outdoor Services, Inc.

- Cocoon

- GreenHome Institute

- London Aire Services, LLC

- HUB Energy Group, LLC

- Minnesota Building Performance Association. 


\section{Executive Summary}

The U.S. Department of Energy Building America Program (BA) goal is to achieve 40\% energy savings in existing homes by 2030 . However, according to a recent study by the Regulatory Assistance Project of leading markets around the United States, less than 2\% of single-family homes have installed whole-house energy-efficiency upgrades that would meet the $40 \%$ energy savings goals (Neme, Gottstein, and Hamilton 2011). Several good programs including Home Performance with ENERGY STAR ${ }^{\circledR}$, utility-funded programs, and federally and state-funded low-income weatherization programs have yet to move the market significantly. Engaging large numbers of homeowners in building science-guided upgrades during a single remodeling event has been difficult for a number of reasons. Performance upgrades in existing homes tend to occur throughout multiple years and usually result from component failures (e.g., furnace failure) and weather damage (e.g., ice dams, roofing, and siding). Financing, information gaps, and competing upgrade desires also prevent consumers from seeking comprehensive improvements.

The NorthernSTAR BA partnership investigated a new model to deploy building science-guided performance solutions to homeowners. This research explored three aspects to market delivery:

1. Understand the homeowner's motivations regarding investing in building science-based performance upgrades.

2. Determine a rapidly scalable approach to engage large numbers of homeowners directly through existing customer networks.

3. Access a business model that will manage all aspects of the contractor-homeownerperformance professional interface to ensure good upgrade decisions throughout time.

The team explored opportunities to deliver upgrades to homeowners by partnering with home service providers. Companies in the $\$ 400$ billion to $\$ 800$ billion home services industry have proven direct marketing and sales proficiencies that have led to the development of vast customer networks. Companies that provide services such as pest control, lawn care, and security have nurtured these networks by successfully addressing the ongoing needs of homes and homeowners. This long-term access to homeowners and trust established with consistent delivery has also provided opportunities for home service providers to grow by successfully introducing new products and services to existing customers. For example, some national companies such as Orkin, LLC, pest control and TruGreen, Inc., lawn care also sell attic insulation and air sealing.

The NorthernSTAR team pursued ways to integrate home performance upgrades into the portfolios of home service companies to utilize their existing customer base and outreach networks rather than create new networks or programs. This report explores models that can position a building science professional in close proximity to a home service company and their customer base to increase best-practice home repairs and upgrades when decision-making moments are at hand. Having this relationship with the homeowner increases the opportunities that information and influence can be represented in the homeowner's remodeling decisions. A long-term relationship provides opportunities to improve a whole house throughout time with appropriate oversight to achieve $40 \%$ energy savings while protecting building durability and occupant health. 
This investigation uncovered three approaches to advance home performance upgrades through partnerships with home service networks:

- Form a working partnership with national home service franchises that are already installing insulation and air sealing. The success of this approach requires a high level of engagement-i.e., DOE leadership working with company leaders to teach and advocate building science best practices.

- Encourage regionally positioned companies that have demonstrated the capacity to internally manage multiple home services, including energy-upgrade services, to add performance upgrades to their portfolio.

- Create an intermediary organization(s) that introduces, manages, and promotes relational and referral activities that are desired but often difficult to execute for smaller, localized businesses and entities. Capitalize on established homeowner networks to roll out home performance products and services. Manage relationships among businesses/entities, home performance companies, and homeowners to identify opportunities to apply building science-guided upgrades throughout time.

The NorthernSTAR team learned about the HUB Energy Group, located in Cincinnati, Ohio, that began testing a multilevel business and homeowner network that can provide a business model of the homeowner relationship management mentioned in the above paragraph. With years of remodeling and national lead-generation experience, HUB works with building science professionals to connect homeowners to home performance solutions and quality contractors through an extensive referral partner and trade contractor network. At the suggestion of the NorthernSTAR partnership, HUB is now working to engage home service companies as well as a variety of others. 


\section{Introduction}

The Building America Program (BA) goal of deploying energy savings of $40 \%$ or more in existing homes by 2030 also considers building durability and human health and safety. To achieve this goal, BA has been developing and deploying well-researched home performance upgrade measures and packages that address multiple aspects of homes in an integrated way. For example, a BA report on energy-saving measures for existing homes identifies packages of bundled measures that were modeled to achieve $15 \%$ and $30 \%$ savings in 37 locations throughout the United States for mixed-fuel and all-electric houses (Casey and Booten 2011). Average annual savings relative to annual source energy savings were identified. Optimum retrofit packages for higher energy-savings levels, some reaching $60 \%$, were also included. Several reports, however, indicate that most homeowners do not buying bundled energy measures.

According to a recent study by the Regulatory Assistance Project of leading markets around the United States, less than $2 \%$ of single-family homes have undergone whole-house energy upgrades sufficient to meet the 2030 goals - even with the availability of the BA bundled measures and programs such as Home Performance with ENERGY STAR ${ }^{\circledR}$, utility-funded programs, and federally and state-funded low-income weatherization programs (Neme, Gottstein, and Hamilton 2011). This statistic is further supported by a study for the U.S. Department of Energy (DOE) Office of Energy Efficiency and Renewable Energy that found that less than 1\% of homes have had energy retrofits specifically to save energy (Lee 2010). This difficulty in engaging homeowners in home performance is not a new phenomenon. A report by Fuller et al. (2010) from a 1980 to 1992 Bonneville Power Administration program that provided free audits and highly subsidized retrofits found that only $5 \%$ of eligible customers sought an audit.

The NorthernSTAR BA team investigated a homeowner-engagement process not currently used by the home performance industry that could rapidly raise awareness for the benefits of bundled energy retrofits and encourage homeowners to engage in building science-guided energy upgrades throughout time to meet BA goals. The team focused on various sectors of the home services industry — including pest control, lawn care, home security, and others - to better understand their successful businesses and relationships with homeowners. Many of these companies have been able to introduce existing clients to new products and services to engage them in making additional purchases from their originally offered service provider. A few have successfully introduced homeowners to energy upgrades such as insulation and air sealing. 


\section{Background: Homeowners Resist Installing Energy Upgrades}

Although plenty of information exists to make homes more energy efficient, the home performance industry and the design, build, and remodeling industries have had difficulty engaging consumers in building science-guided upgrades. The BA statement of need notes that one of the main problems in getting homeowners to choose energy upgrades is that many people know they will be forced to upgrade when a product fails, ages, or incurs a weather event that damages the system, so they wait until that happens. ${ }^{1}$ Homeowners typically upgrade their homes when forced to do so (in "pain") rather than proactively because of a desire to do so. Many upgrades occur during the course of multiple years as needed rather than being bundled together for efficiency.

In a survey of nearly 500 home performance professionals, four barriers to audits and upgrades were recognized:

- Consumers lack inertia due to lack of time, hassle, and general difficulty accessing information.

- Consumers have limited access to financial resources needed for improvements.

- Consumers lack awareness.

- Home performance services are unavailable in many locations (Palmer et al. 2011).

The study found that providing information to homeowners about their home's energy performance is not enough to motivate them to take action. The professionals reported that only $29 \%$ of homeowners make at least one recommended improvement half the time or less. When asked to speculate why more homeowners do not get audits, the top responses included their beliefs that homeowners feel they cannot afford upgrades recommended by an audit, and homeowners do not know what audits are and what types of information they provide. The survey also found that in geographic areas where government incentives were available, respondents did not report more homeowner follow-up to energy upgrades. When respondents were asked what tactic would be the most helpful in getting homeowners to retrofit their homes, the number-one choice was higher energy prices. Ironically, they cited more government rebates and subsidies as the second most important step (Palmer et al. 2011).

The Regulatory Assistance Project echoed these results when it studied the reasons why consumers fail to invest in home performance upgrades (Neme, Gottstein, and Hamilton 2011). It also identified consumer barriers to whole-house retrofits:

- Consumers have inadequate access to capital.

- Consumers lack sufficient and credible information about the inefficiency of their homes and the benefits of upgrades.

- Finding qualified contractors and getting the work done can be a hassle for consumers.

\footnotetext{
${ }^{1}$ According to an internal communications request for proposals from a 2013 BA statement of need, "FY 2014 Department of Energy Residential Energy System Research Needs.”
} 
- Most efficiency improvements are not attractive or visible; they have less show-off value.

- Most contractors have weak sales skills to effectively promote whole-house retrofits (Neme, Gottstein, and Hamilton 2011).

Getting to the heart of consumer motivation for energy upgrades was the focus of a report that studied the motivations of home sellers compared to home buyers and the role of an energy performance label for existing homes (Newport Partners 2010). Contrary to the survey results found by Palmer et al., Newport Partners found that consumers cited saving money as the most compelling reason to invest in energy upgrades. Spending money on an audit to understand energy waste, however, was not a motivating factor for homeowners or home sellers. On the other hand, homebuyers were more likely to conduct home-energy analyses at the points of sale and were willing to pay $\$ 200$ to $\$ 400$ for these independent analyses. The primary motivation to seek an audit was to use the findings to negotiate the sales price with the homeseller. Both homeowners and homebuyers were reluctant to finance energy improvements by using long-term loans; they preferred to pay for improvements with savings or short-term, $0 \%$ financing. Emergencies become priorities.

A report reviewing 30 years of energy-efficiency programs addressed another problem with engaging consumers in comprehensive energy retrofits (Fuller et al. 2010). Success has been limited in energy-efficiency program development and deployment to provide direction to new program developers on how to reliably motivate large numbers of Americans to invest in comprehensive home energy improvements. The lessons learned from reviewing energyefficiency programs that were able to achieve some level of success included:

- Sell something people want, such as comfort, practical investment, self-reliance, or being part of the social norm.

- Define an audience to target, and tailor messaging to it.

- Partner with trusted messengers.

- Expose the target audience to a message multiple times. Persistence and consistency are key.

- Include incentives such as financing and rebates.

- Collect data, and measure success (Fuller et al. 2010).

Approximately 100 million homes in the United States can be considered no longer new (10 years old or more), and therefore they may benefit from performance upgrades. How are home performance upgrades initiated, and how are they completed safely and correctly? According to a 2014 report, the remodeling industry reached approximately $\$ 400$ billion in sales (EagleMac 2015). Homeowners will endeavor to remodel in small and possibly unrelated increments throughout a period of time. The following represent major categories of home upgrades:

1. Homeowner-initiated upgrades:

A. Major events (These are in the "pain" category.)

i. Storm damage

ii. Fire 
iii. Flood (caused by internal or external elements)

iv. Furnace or air-conditioning unit failure

v. Ice dams and subsequent mold and rot

vi. Other required repairs or replacement due to age and wear.

B. Redecorating/remodeling (These are in the "desire" category.)

i. Adding a room

ii. Remodeling or upgrading a kitchen

iii. Adding a bathroom.

C. New homeowner. A buyer often initiates remodeling right away (Scarborough 2013).

D. Homeseller. A homeowner may "spruce up" or remodel in preparation to sell a home to make a profit.

2. Non-homeowner remodeling

A. Flippers for profit. This group does not live in the house.

B. Urban, nonprofit, affordable-housing rehabilitation. This is often major renovation.

C. Affordable programs often supported by the government.

i. Weatherization

ii. U.S. Department of Housing and Urban Development requirements.

Because most upgrades are potentially related to heat, air, and moisture issues, building science guidance, testing, and risk management should be considered. The key to ensuring appropriate guidance for energy upgrades is to significantly increase the probability that building performance experts will be present and part of the decision-making processes when the needs for energy upgrades occur.

Although less than $2 \%$ of homes in the United States have completed whole-house upgrades, many have completed some form of energy-related retrofit or analysis. Table 1 outlines the energy upgrades by type (U.S. Energy Information Administration 2009).

Table 1. Number of U.S. Homes with Energy Upgrades

\begin{tabular}{c|c}
\hline Metric & Number of Homes \\
\hline Added insulation & 25.5 million \\
\hline Added weather stripping/caulking & 40.8 million \\
Replaced all windows & 16.8 million \\
Use energy-efficient lightbulbs & 68.1 million \\
Had energy checkup performed & 4.6 million \\
\hline
\end{tabular}

What is not known about the above information is how much of the work was bundled together and how much was or was not guided by building science principles. Upgrades void of building 
science context or lack of a sequencing approach that considers the house as a system may put the home and the occupants at risk or result in extra expenses (Neme, Gottstein, and Hamilton 2011). Some of these risks include:

1. Insulation installed without proper air sealing or concern for combustion safety

2. Lost investment when duct work is insulated in an attic that will someday be inside the thermal boundary

3. New heating equipment that eventually becomes oversized when the air sealing and attic and wall insulation are added after the equipment is installed

4. Renewable systems that become oversized because they were installed prior to a wholehouse upgrade.

The sequence of incremental upgrades is critical. The importance of appropriate sequencing for remodeling and upgrading homes was detailed by Patrick Huelman via an historical lens in light of the rising demand for energy efficiency in homes (2014). Huelman reviewed efforts by the housing industry to improve energy efficiency since the energy crisis of the 1970s. Through the unintended consequences of improper sequencing - for example, adding insulation and windows without resolving critical air, moisture, or bulk water problems; tightening the building enclosure before addressing ventilation; or upgrading furnaces without considering the water heater and its ability to safely vent toxic gases - a critical pathway for improving energy-efficient, healthy, safe, and durable homes emerged. Figure 1 illustrates the order of remodeling activities proposed by Huelman to minimize risk to the house and occupants.

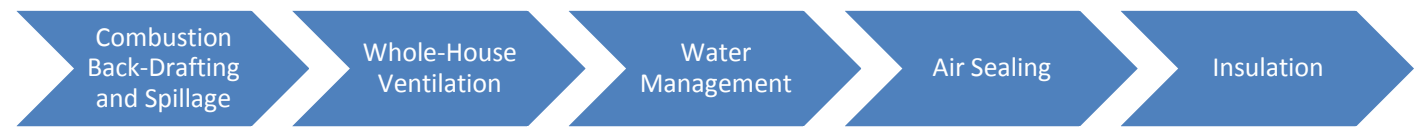

Figure 1. Order of remodeling activities to reduce risk (Huelman 2014)

All other upgrades - windows, mechanical equipment, renewable-energy sources or appliances - are best added after the first five concerns are addressed. Additionally, a test in process can document the existing conditions and fragility of a home to inform and guide work scopes and budget. A test-out process helps ensure proper performance of the house and its installed systems. By understanding proper sequencing, professionals and homeowners can learn from the lessons of the past rather than repeat mistakes. Table 1 highlights the continuing popularity of adding insulation as an energy solution rather than having energy audits. This suggests the heightened need to educate professionals and homeowners.

However, more than information is needed to motivate professionals and homeowners to act to achieve the BA 40\% energy savings goal. The new construction, home improvement, and home performance industries have yet to achieve industry-wide success in the market adoption of bestpractice energy solutions even with the availability of easily accessible information. Although the new construction industry has had some success in creating energy-efficient homes, the methods used to market energy efficiency to buyers of new homes are not always transferable when selling products and services to existing homeowners. The homeowner's expectation for energy efficiency may be different, the pathways to upgrade an existing home are often different 
than the pathways to create a new energy-efficient home, owners of existing homes may have priorities for remodeling activities that supersede energy-efficiency desires, and financing or costing options are different.

The factors that motivate owners of existing homes to choose building science-guided upgrades have yet to be defined and developed into an effective, scalable deployment system. The NorthernSTAR team intends to develop a clear pathway to a deployment system that utilizes existing market methods and partners that have had success motivating homeowners to act.

\subsection{Developing Customer Networks}

A close look at the vast home services industry demonstrates one universally common component among these companies: their successful ability to market directly to homeowners to get them to act. Angie's List puts the home services industry at $\$ 400$ billion and others as high as $\$ 800$ billion (Stout 2015) as online marketing of home services rapidly grows. Google is investing \$100 million in Thumbtack, a purveyor of home services. Amazon launched Amazon Home Services to provide their 85 million customers with a list of vetted and insured professionals who deliver more than 700 services to install and assemble products purchased on the site. The online service also provides price quotes and scheduling help (Stout 2015).

Still, the majority of home service businesses that create repeat customers - such as pest control, lawn care, cleaning, landscaping, window washing, and chimney sweeping - use telemarketing, door-to-door and relational sales, customer referrals, and various media to win customer confidence, build loyalty, and gain repeat business. These approaches have a proven track record of delivering high-velocity market services to homeowners along with success in selling new ideas. Many companies in these industries - including ServiceMaster, Terminix, Orkin, and TruGreen - have repeat, long-term access to homes and homeowners, often multiple times per year. The residential and commercial pest control industry comprises nearly $\$ 11$ billion in annual revenue, 22,000 licensed operators in the United States, and 150,000 employees (Steinau 2011). The residential and commercial landscaping services industry represents $\$ 73$ billion in annual revenue and employs more than 971,000 people (IBISWorld 2015).

\subsection{Following Building Science Principles}

The initial literature review found that several national companies sell select energy upgrades alongside their traditional products and services. For example, TruGreen lawn care offers insulation services to lawn care clients to help improve the comfort of their homes (2015). However, there is no indication that they are following best practices. According to a call to a TruGreen salesperson, installers add insulation to attics without any air seal or testing. As another example, Orkin pest control offers insulation products and services, but it does not indicate on its website whether insulation installers air seal or test (2014). On one hand, it is beneficial that these companies offer insulation and help improve the energy efficiency of homes; on the other hand, however, they may be compromising the indoor air quality and durability of the homes for the homeowners. One question to answer is how the building science community can work with these large home service companies to implement best practices and reduce the risk in the homes where they are applying energy measures.

Working with home service providers may be an ideal pathway to reach homeowners who are in a position to upgrade their home but do not have access to appropriate building science guidance. 
These companies are often in close proximity to homeowners when home services are needed, and they are present when decision-making moments are at hand. Home service companies have trusting relationships with homeowners, so they could present sound information and influence the homeowners' remodeling decisions. Tapping into these existing customer networks would be more efficient and effective than creating new ones.

The first part of NorthernSTAR's goal is to determine how to access the massive customer networks that already exist. The second part of the goal is to determine how to engage home service providers to work with building performance specialists to guide, sell, and install performance upgrades through their networks. Ultimately this approach will benefit home service businesses through increased sales as service portfolios grow. Broad demand for home performance upgrades could result in jobs creation. It could also lead homeowners to wholehouse energy efficiency, reduced energy consumption, improved home performance, home durability, and better occupant health. 


\section{Research Process}

The promising component of engaging home service companies to deliver home performance upgrades is that many home service providers have established relationships with homeowners. These networks exist in virtually every city in the country, and their sales and marketing foundations have been proven effective. In addition, some sector leaders already offer energy upgrades as part of their portfolio of services. What needs to be understood is if the home services industry can be a pathway for encouraging the adoption and promotion of building science-guided upgrades, and, if so, what methods and mechanisms can be developed to manage and connect home service companies to best-practices information and the existing marketplace of home performance professionals. Answering these questions will go a long way toward advance the BA 2030 energy-saving goals.

\subsection{Guiding Questions}

An initial literature review by the NorthernSTAR BA team highlighted the revenue successes of several home service sectors known for high-velocity marketing and relational sales. It also pointed to the trend of companies offering energy upgrades alongside their primary services. Four of the top 10 pest control companies provide select energy upgrades (e.g., insulation and air sealing) to homeowners along with pest control (Univar 2014).

The team attempted to gain a better understanding of the extent to which performance upgrades were offered by these home services companies. The team also wanted to understand what key business strategies helped these companies integrate unrelated services into their portfolios and how these companies could potentially become conduits for building science-guided upgrades. Referrals were often mentioned as an important means for generating revenue. These key highlights helped develop the following set of questions as a guide throughout the literature review and investigative actions:

1. Is it feasible to use the home services industry to deliver building science-guided home performance upgrades?

2. What company characteristics would most likely facilitate the successful integration of building science-guided upgrades into an existing portfolio of services?

3. What opportunities exist through referral networks to advance home performance upgrades?

4. What could be the expected scale and speed of moving this synergy into place?

\subsection{Literature Review}

Initial research into the idea that home service companies might be a viable method for delivering home performance solutions provided promising results while also introducing many more questions. Understanding the extent to which performance upgrades play a role in the portfolios of home service companies and why could provide insight into how receptive companies may be to the idea of offering building science-guided upgrades as well. An expanded literature review was conducted for discovery. It was also conducted to develop questions that could guide additional research. 


\subsection{Interviews with Key Personnel from Home Service Companies}

Although some industry leaders in each home services sector already engage in energy upgrades, many smaller, localized businesses do not currently offering these options. Interviews with key personnel were used to help assess the following:

- Structure of their businesses

- Interest in the concept of adding performance upgrades

- Ability to add home performance services to their portfolios

- Perceived pros and cons of adding energy upgrades

- Steps to move forward with energy upgrades.

\subsection{Questionnaire for Home Performance Professionals}

The members of the Minnesota Building Performance Association (MBPA) actively promote building science-guided upgrades to homeowners in and around the state. Many members secure work as subcontractors to utility companies and their subsidized energy audit programming. To understand MBPA member interest in developing nontraditional avenues to connect with homeowners, an online questionnaire was sent to their 100 active members. Questions sent to the MBPA members can be viewed in Appendix A. 


\section{Investigation}

\subsection{Home Service Providers Show Success in Marketing to Homeowners 4.1.1 Pest Control}

The massive customer networks developed by home service providers indicate the large potential to initiate sales in home performance upgrades. However, none of the companies interviewed were willing to share their percentage of sales attributed to home performance measures. The initial literature review indicated that the pest control industry may be the likely leading sector in the home services industry to provide energy upgrades to homeowners. Following is a sample of companies from Pest Control Technology magazine's Top 100 list of pest control companies for 2013 (Univar 2014).

Orkin is a wholly-owned subsidiary of Rollins, Inc., located in Atlanta, Georgia. Rollins, which has numerous pest control brands, is ranked number one in pest control and has $\$ 1.34$ billion in annual revenue, $59 \%$ of which is from residential customers (Univar 2014). The company provides their services to homeowners through locally-owned franchise operators. The Orkin brand is advanced through franchise operators who are provided corporate support for training and technical solutions, call center services, sales and marketing materials, existing customer and supplier relationships, and the purchasing power of Rollins. Consumer trust is nurtured through dependable service, uniformed representatives who drive company vehicles, and continuous communications. Success in pest reduction is promoted through solutions customized to individual homes and problems (Orkin 2015).

In addition to applied pest control solutions, the company offers (1) OrkinTherm, a blown-in, potentially money-saving insulation with pest control and ENERGY STAR label available to purchase at retail locations or for installation by an Orkin professional; (2) Orkin DryZone crawl space and basement solutions to eliminate or reduce moisture to deter pest infestation; (3) Orkin ComfortZone radiant barrier for attics and garages to promote energy efficiency; and (4) Orkin Leaf Stopper, a gutter insert treated with biocide and fungicide that is designed to prevent leaf buildup so gutters remain clear of standing water and pest breeding grounds (Orkin 2014).

The Rollins umbrella of pest control companies also includes Western Pest Services that serves clients in the northeastern United States from Connecticut to Virginia. Western Pest Services promotes the prevention of pest entry through integrated pest management techniques such as caulking and air sealing. They also offer home maintenance programs to reduce future pest infestations including ThermoZone Attic Insulation with added pest control. Western Pest Services offers solutions that deter pest nesting and breeding by reducing bulk water and vapor by way of their Vaporshield Moisture Control solution for crawl spaces, gutter cleaning, and an installed gutter protection system (Western Pest Services 2015).

Terminix, a ServiceMaster company located in Memphis, Tennessee, is ranked number two and has $\$ 1.3$ billion in annual revenue, $80 \%$ of which is from residential customers (Univar 2014). Services are provided in the United States by a network of company-owned branches and franchised units. Sales are encouraged through a credit on a customer's future billing for each new referral that signs up for a Terminix service. Consumer trust is nurtured through repeated dependable service, uniformed representatives who drive company vehicles, and continuous 
communications. Success in pest reduction is promoted through solutions customized to individual homes and problems (Terminix 2015).

In addition to chemical applications, the company offers pest solutions such as (1) "more comfort" cellulose insulation with the ENERGY STAR label and pest control; and (2) crawlspace vapor barriers, temperature vents, and encapsulation services. To correct support issues caused by water, heat, and termites, Terminix will provide crawl-space floor supports.

Rentokil, headquartered in Reading, Pennsylvania, has regionally branded pest control companies in most U.S. states. It is ranked number four and has $\$ 353$ million in annual revenue, $40 \%$ of which is from residential customers (Univar 2014). Ehrlich, one of the Rentokil companies located in the eastern United States and Midwest, provides integrated pest management techniques before chemical applications. Integrated pest management includes air sealing and caulking as well as control of relative humidity, light, and temperature to deter pest nesting and breeding. Success in pest reduction is promoted through solutions customized to individual homes and problems (Ehrlich 2014).

Arrow Exterminators, located in Atlanta, Georgia, is ranked number six and has \$135 million in annual revenue, $84 \%$ of which is from residential customers (Univar 2014). Consumer trust is nurtured through repeated dependable service, uniformed representatives who drive company vehicles, and continuous communications. Arrow is also Quality Pro certified through the National Pest Management Association to acknowledge their excellence in meeting standards for business operations, customer satisfaction, environmental stewardship, and training. Success in pest reduction is promoted through solutions customized to individual homes and problems (Arrow 2014).

In addition to chemical solutions, Arrow offers pest control services such as (1) cellulose insulation treated with boric acid for pest control and "to reduce costly energy bills"; and (2) moisture control through automatic foundation vents, gutter and gutter guards, crawl-space vapor barriers, and encapsulations. The company also offers lawn care and handyman repairs and replacement services for windows and sills, doors, drywall, siding, and others.

ABC Home \& Commercial Services, located in Austin, Texas, is a pest control company ranked number 14 and has $\$ 51$ million annual revenue, $65 \%$ of which is from residential customers (Univar 2014). Consumer trust is nurtured through repeated dependable service, uniformed representatives who drive company vehicles, continuous communications, and promotion of the Quality Pro industry designation. Success in pest reduction is promoted through solutions customized to individual homes and problems. Their ABC Customer Rewards program was developed to encourage current clients to try other services that $\mathrm{ABC}$ has to offer. For each service purchased, a customer is rewarded points that can be redeemed for future ABC products and/or labor.

In addition to applied pest control services, the company offers an extensive list of home improvement, repair, and maintenance services including heating, ventilating, and air conditioning (HVAC); electrical; plumbing; painting; handyman; and full remodeling such as additions, kitchens, porches, and media rooms. Their AC \& Heating Services include repairs of air-conditioning and heating units; tune-ups; and a Home Comfort Analysis inclusive of 
inspections, a blower door test, air-leakage evaluation, and airflow diagnosis. ABC Electrical Services includes ceiling fan installations and kitchen exhaust hood installation. Plumbing services include water heater installation and natural gas leakage testing (ABC 2014).

Guardian Pest Solutions, located in Duluth, Minnesota, is ranked number 76 and has yearly revenues of $\$ 9$ million, 10\% of which is from residential customers (Univar 2014). In addition to offering integrated pest management, mold solutions, and Quality Pro certification, they are Green Pro Certified, which acknowledges their commitment to providing pest management that is least risk to people, property, and the environment (Guardian Pest Solutions 2014).

Magic Pest Control, located in Phoenix, Arizona, uses a deterrent approach that employs caulking and air sealing at typical entry points as one of its methods to reduce scorpion access to homes (Magic Pest Control 2015).

\subsubsection{Lawn Care}

The residential and commercial landscaping services industry represents $\$ 73$ billion in annual revenue and employs more than 971,000 people (IBISWorld 2015). In a research project by Lawn \& Landscape magazine, a random sampling of their 18,639 subscribers provided insight into revenue and profits. In general, $67 \%$ of sales come from single-family residential properties. Gross sales for $73 \%$ of the companies were less than $\$ 499,999$. Only $15 \%$ of the survey respondents predicted gross sales in excess of $\$ 1$ million. The greatest economic challenge, represented by $25 \%$ of respondents, is having better candidates for open positions (Lawn \& Landscape 2013).

Like the pest control industry, some lawn care companies sell energy upgrades. TruGreen, which has annual revenues of $\$ 979$ million and 10,000 employees, is the second largest lawn care company in the United States. It also offers residential insulation services by installing ENERGY STAR labeled cellulose attic and wall insulation to promote energy efficiency and comfort (TruGreen 2015).

A sampling of small, locally-owned home service companies indicated that some offer insulation services alongside lawn care services:

- Elite Energy Solutions, located in Lindon, Utah, offers attic and wall insulation, duct sealing, energy audits, pest control, and lawn care (Elite 2015).

- Advance, located in Hutchinson, Kansas, offers termite and pest control, lawn care, and pest control insulation (Advance 2015).

- Lake Norman Pest Control, located in Lake Norman, North Carolina, offers pest control services, pest control insulation, and lawn care (Lake Norman Pest Control 2015).

\subsubsection{Home Security}

Residential business in the home security industry accounts for $\$ 98$ billion per year, or 35\% of the total $\$ 280$ billion electronic security market. In this sector, $95 \%$ of home security companies sell methods to prevent or detect intrusions, and $12.6 \%$ sell and install home energy management systems (Security Sales and Integration 2014). No large home security companies appear to offer energy retrofits as part of their service portfolio. 


\subsubsection{Chimney Sweeping}

The 2011 National Chimney Sweep Guild and Chimney Safety Institute of America survey provided an overview of the industry revealing that 5,000 chimney sweep companies total $\$ 2$ billion in yearly revenue, $42 \%$ of which is from repeat customers, and $23 \%$ of customers originate from referrals. The mean average size of a chimney sweeping company comprises five full-time employees and a gross revenue per survey respondent of $\$ 437,000$ annually (Chimney Safety Institute of America 2012). No chimney sweep companies were found to offer energyupgrade services.

\subsection{Interviews with Key Personnel from Home Service Companies 4.2.1 Outdoor Services, Inc.}

Outdoor Services, Inc., (OSI), located in Bismarck, North Dakota, specializes in lawn and tree care. With a customer base of 3,000 clients and gross annual sales of $\$ 4.5$ million, it is ranked among the top 15 lawn care companies in the United States. ${ }^{2}$ The owner states that dependability is the company's most important attribute and claims an $80 \%$ to $85 \%$ customer retention rate with the majority of customer loss due to moving.

The owner opened a call center and database management business in Bismarck that offers telemarketing services to lawn care companies throughout the United States. In 1986 he launched OSI lawn care service as a "marketing company that provides services for pain management." The owner wanted to focus on a type of business that would provide repeat revenue with little effort-i.e., lawn and tree care customers were easy to acquire through cold calls, door-to-door, and relational sales.

The company rarely uses cold-calling today. Instead, using the company's database, sales representatives call current customers to follow up on a provided service or connect with homeowners that sought online estimates using the company's web-based aerial-imaging software. Today OSI uses postcards, brochures, and billboards as marketing tools. The owner, who still prefers to get into homes for relational sales, continues to connect with people by going door-to-door.

New clients are found through the owner's other business, SunnyMaids residential house cleaning. Managers of OSI and SunnyMaids meet regularly to discuss opportunities to sell services from one company to clients of the other.

When OSI considered business expansion in the past, potential services were evaluated based on what is easy to sell or is already selling well in other markets or by other companies-i.e., it is much easier to sell a service when people are aware of its benefits. OSI typically focuses on a business model that provides maximum profit with little internal effort unless it provides joy or fulfills a passion for the owner and managers. Some of the key considerations when evaluating new services to offer include:

- How is money made via the service?

\footnotetext{
2 According to a personal interview on August 29, 2014, with Dale Preszler of OSI, located in Bismarck, North Dakota.
} 
- Who is willing to pay for it?

- What percentage of current customers would find it useful or necessary?

- How difficult will it be to develop market awareness?

- How easy is it to train employees to provide quality service?

- What is the overall liability?

OSI began selling external (perimeter) pest control and irrigation services after reviewing opportunities for profit and overall liability; thus, OSI offers only external pest control solutions, not internal pest solutions, due to the increased liability of working inside a home. These supplementary services are marketed through correspondences with lawn and tree care customers. OSI also markets these services on door hangers when leaving a lawn care estimate for a potential new client.

The owner views upgrades such as air sealing and insulation as having intriguing business potential. Currently many employees face reduced hours or layoffs during the winter months. Having a portfolio of services that can be undertaken year-round would be helpful in retaining quality employees. It would also reduce the cost of training new employees each season. However, OSI has limited knowledge about residential construction to understand if components are easy to sell, what types of awareness exist in the marketplace for these services, what types of employee training would be needed, and what levels of risk the company would face by installing energy upgrades and working inside a home.

OSI tends to prefer referral relationships with other companies rather than adding and fulfilling services internally. However, they would only refer another company to an OSI client if they are confident that that company would follow up in a dependable, timely fashion and provide good service that would reflect positively on OSI.

\subsubsection{GreenHome Institute}

GreenHome Institute (GHI), formerly known as the Alliance for Environmental Sustainability, is a nonprofit business based in Grand Rapids, Michigan, with yearly revenues of $\$ 450,000$. It provides technical support, energy auditing, and green home certification and education on high performance homes and green building programs to residential developers, builders, remodelers, home performance professionals, and homeowners in Michigan and neighboring states. ${ }^{3}$ The executive director does not describe the organization as a traditional home services company but one that works with homeowners to connect them to information and services to facilitate the creation of greener homes. They also partner with a variety of city and state programs to connect homeowners to incentives for greener behaviors. GHI works with the city of Grand Rapids, Michigan, and its My GR City Points program. Residents and nonresidents can earn points through the program when they recycle, volunteer, or participate in community building. They can also earn points through GHI when they schedule an energy audit or healthy home review. Points can be redeemed at local businesses for discounts on products and services.

\footnotetext{
${ }^{3}$ According to a personal interview on July 11, 2014, with Brett Little, executive director of Green Home Institute, located in Grand Rapids, Michigan.
} 
In a discussion with the executive director of GHI, the nonprofit would be interested in exploring ways to engage more homeowners in home audits, healthy home reviews, and follow-up actions. The professionals GHI works with to perform energy audits are being trained to encourage homeowners to take action after an audit in what they call "opportunity upgrades," helping homeowners address problems at the appropriate opportunity by reporting what needs to be done in their homes and when.

The concept of partnering with a home services company in a referral relationship to raise awareness of GHI services and to advance the number of homeowners engaging in home assessments and action is appealing to GHI. How a referral relationship would work with their nonprofit format and focus on green homes would need to be explored. It is clear that GHI could benefit when a partner refers clients to GHI for an audit, but it is not clear how GHI could reciprocate referral fees or referrals to services not tied directly to green homes.

\subsubsection{Adam's Pest Control}

Adam's Pest Control, Inc., (APC) is a family-owned company in business since 1971 that specializes in residential and commercial control of insects, wildlife, and bed bugs. ${ }^{4}$ The company has $\$ 8.5$ million in yearly revenue, 75 employees, and 2 office locations in Minnesota. They promote pest control through best practices with emphasis on sanitation and exclusion before the application of chemicals and rodenticides. Growing concerns to protect the environment and an increased focus on personal health has led the company to diversified solutions that are more earth friendly. APC has an on-staff entomologist to test products and application systems as well as to conduct field studies prior to using them with customers.

In an interview with the residential division manager, it was learned that APC has considered offering borate-based insulation to homeowners. At the time of review, it was not considered a strong revenue generator. However, there has been interest in the past to better understand air leakage and how pests get into homes so that air-leakage solutions could be used to reduce the need for chemicals. The cost of an independent blower door assessment per house has been a barrier in the past for pursuing this solution. Whether air-sealing work occurs through a referral partner or by an in-house employee has not been investigated, and no comment was made.

One reason APC would investigate opportunities for adding energy-upgrade services to their pest control business would be to provide employees with work during the off-season without reducing their payment. This provides a second benefit to the company by eliminating training costs and learning curves for new hires.

\subsubsection{Cocoon}

Cocoon is a small business located in the Minneapolis, Minnesota, region that provides home performance testing services, insulation installation, and radon testing and mitigation. ${ }^{5}$ The owner of the company was intrigued by the idea of developing a referral relationship with another business to promote each other's services and advance home performance awareness. In

\footnotetext{
${ }^{4}$ According to an interview on November 4, 2014, with Mike Richard, residential division manager of Adam's Pest Control, located in Medina, Minnesota.

${ }^{5}$ According to a personal interview on July 28, 2014, with Steve Schirber, owner of Cocoon Solutions, located in Eden Prairie, Minnesota.
} 
the interest of exploring this opportunity, the owner met with a residential window washing company that has 4,000 active clients to discuss opportunities for promotion.

Although each person agreed that a referral relationship could be beneficial to growing revenue, there were several hurdles that would need to be addressed. For example, the referral partners would need to develop rules of engagement and compensation, develop marketing literature and support to help the referral partner promote services, and create business methods to track referrals and compensation. The owner of Cocoon would need to hire a part-time or full-time employee to develop and manage the referral relationship as well as to follow up on leads that are generated by the referral. It would also require Cocoon sales and installation personnel to actively promote the referral partners services - a step requiring training. At this time, the owner decided that his small business was not in a position to pursue this relationship. When our team proposed the idea of a third-party management system to manage the referrals for them rather than having to do it in-house, the owner of Cocoon commented that he thought this scenario would be ideal.

\subsubsection{London Aire Services, LLC}

London Aire Services, LLC, is an independently owned small business serving the metro area of Minneapolis and St. Paul, Minnesota, since 1987. The company specializes in chimney inspection, cleaning, and repair and dryer duct inspection and cleaning. It prides itself on its $\mathrm{A}+$ rating with the Better Business Bureau through years of building reliable, on-time, professional services. Although the owner did not have specific numbers to provide, he did state that the majority of new clients are generated from referrals from satisfied customers.

The owner has been a witness in law suits related to mold issues and make-up air problems, which has led him to seek further education on air quality and health. The owner is not interested in expanding his business to offer energy-related services such as insulation or air sealing. He is somewhat interested in the idea of a referral arrangement with other businesses because some clients have asked him about ways to improve the comfort of their homes.

He would enter into a referral relationship with another business only if the other business was educated in building science and promoted it through the actions of their company; he would not promote a business that installs energy upgrades without considering the impact on health and safety. Additionally, the owner would pursue a referral relationship only with businesses that have proven to him that they can act in an equally trustworthy and reliable manner with his clients. $^{6}$

\subsubsection{HUB Energy Group, LLC}

HUB Energy Group, LLC, was formed during the first half of 2014 and began its network concept by serving as a centralized connector of professionals and consumers to solve the energy-efficiency puzzle in the United States. ${ }^{7}$ At its core are four businessmen who bring unique experience, knowledge, and success in remodeling, lead generation for contractors,

\footnotetext{
${ }^{6}$ According to a personal interview on April 7, 2015, with Jim Collar, owner of London Aire Services, LLC, located in Minneapolis, Minnesota.

${ }^{7}$ According to a personal interview on July 20, 2014, with Don Baldwin, CEO of HUB Energy Group, LLC, located in Grand Rapids, Michigan.
} 
customer relationship management, home performance, information technology, and venture capital development. HUB's market delivery model uses a referral-based networking and leadgeneration system to raise awareness and inspire homeowners to take action to improve the energy efficiency, safety, and durability of their homes. The referral networks, supported through an advanced data-organizing platform known as HUB2e, connect homeowners to prescreened, trained professionals enrolled in HUB's trade contractor network to improve the ease of hiring contractors. This online platform is the key to HUB's organization and the vehicle for a national market delivery system that links home performance experts, contractors, suppliers, and homeowners. It tracks data from contractors and homeowners and includes a means for storing home data and history. Homeowners have access to contractor information, social media to connect with other homeowners, and marketing to see the latest upgrade information in their area. They are able to show photos of their latest kitchen remodel or room addition. Finally, homeowners can recruit friends to join or refer them to contractors; this gives HUB two ways to earn referral fees.

The basic concept of HUB's system begins with a homeowner being introduced to the HUB by a referral partner such as an energy-retrofit professional, utility company, home improvement company, retailer, real estate agent, nonprofit organization, or service company by utilizing the free online Home Awareness Evaluation tool. The HUB group encourages the client to complete a free online home evaluation developed by HUB for its partners to use in their daily business interactions with their new and existing customer base. The home evaluation can be sent to the client via a smart phone, tablet, or computer during an in-home appointment or at any other available time. Once a Home Awareness Evaluation is completed by the customer, they receive a customized report via email with different ways to schedule a free in-home assessment, also called a home checkup. The homeowner can do this directly from the email using the built-in scheduling system tied to HUB's home asset management and engagement system. The client is also given the option to contact a HUB representative to discuss the report.

Free assessments are conducted by accessors trained by USAirSeal. USAirSeal conducts home energy assessments and audits coupled with direct installation of air seal and insulation measures. USAirSeal representatives potentially become long-term guides that help homeowners manage their home asset and incremental energy upgrades throughout time. USAirSeal is a division of the HUB Energy Group and has staff with various Building Performance Institute certifications. Upon completing the free in-home assessment, the homeowner receives a link via email to set up their profile, wherein they can find a digital copy of the assessment and a free doit-yourself ebook. Future documents, upgrades to their house, revised score tracking, and performance improvement information are stored in the customer profile for future use-i.e., when selling their house and adding value to a potential buyer. The USAirSeal trained staff use these opportunities to discuss the importance of the energy score, improved performance features of their home, and encourage completion of a home checkup. The information and data collected from the homeowner is uploaded to the HUB home asset management system, which helps the HUB representative guide and encourage the homeowner regarding future performance upgrades.

USAirSeal performs the home checkup for a customer and uploads it to the HUB customer's profile page. A prioritized list of effective efficiency upgrades is then presented to the homeowners for consideration along with available incentives. Upgrades are performed by 
HUB's home performance contractors. Financing is available to help the homeowner facilitate needed upgrades. The cost of financing can in some cases create a net zero cost to the homeowner due to savings on future utility bills. The HUB Energy Group is currently developing an auditing platform (E-spect) that will deliver data directly to the HUB while identifying potential upgrade leads to present to HUB's home performance contractors. The platform will also be used in the future to generate the Home Energy Score developed by Lawrence Berkeley National Laboratory and DOE (Figure 2). All data gathered in the HUB system will be used to create targeted marketing campaigns for clients to continue to take action on future upgrades. Contractors will provide incentives or coupons for future work based on the data. Also, the profile data helps USAirSeal track upgrades to watch for risky sequencing, and it can better advise homeowners before they make remodeling decisions.

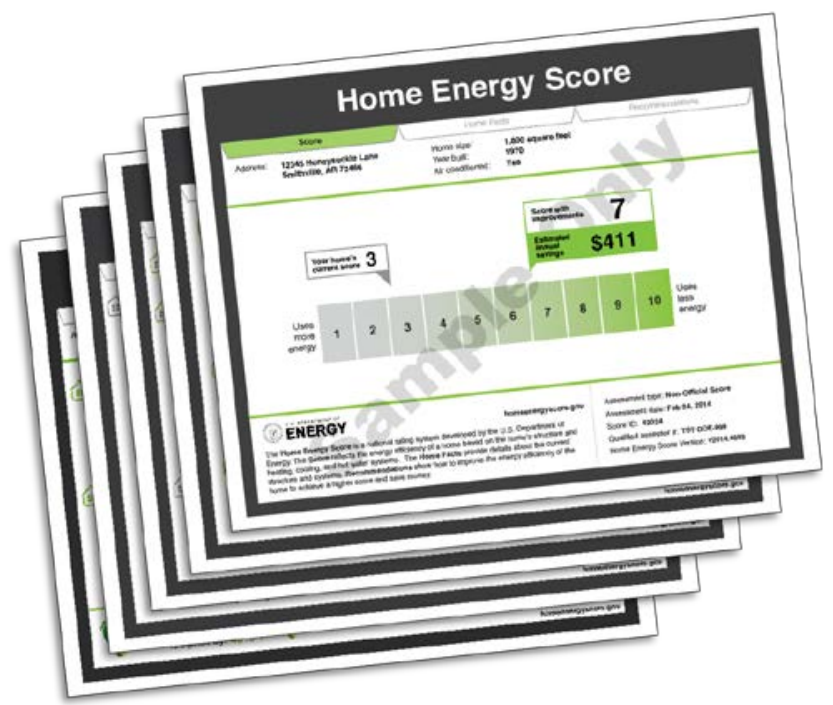

Figure 2. DOE Home Energy Score label

To encourage long-term engagement with the HUB, homeowners who have completed an online home score are given a free portal in the online system wherein audit and upgrade information, documents, data, and photographs can be stored for personal review and use. The portal provides the homeowner with information from HUB about incentives, opportunities to share ratings on trade contractors, and a means to connect with other HUB homeowners via the HUB's social platform. HUB marketing virally connects the consumer to a system that encourages them to complete additional retrofit projects to achieve further energy-reduction results. The HUB2e process continually cycles back to the consumer for future work by remaining valuable, meaningful, and memorable through incentives and available rebates.

When a homeowner completes an upgrade through HUB, the original referral partner is compensated for the lead and receives a commission on all future work completed by the homeowner; this provides an incentive to the referral partner to continue to refer clients to HUB. The homeowner that received the service is encouraged to become a referral partner to refer family and friends and thus receive commissions on their upgrades. HUB has also created a process whereby referral partners can pass along HUB information, energy-saving opportunities, 
and incentives to clients via marketing materials that can be custom branded to include personal or company information.

The HUB Energy Group started their concept in the southern Ohio market with a focus on the city of Hamilton, which has a population of $63,000,30,000$ of which are rate payers. The City of Hamilton owns its utilities and is working at achieving energy independence along with energy efficiency and sustainability for all its buildings. The city staff has agreed to work with the HUB program to align it with the city's programs that help to engage citizens. Since September 2014, when the beta testing began, the HUB Energy Group has been able to sign 13 contractors and home improvement vendors into the program including remodelers, builders, a mechanical equipment dealer, and roofing and siding specialists.

Scherzinger Pest Control, a Cincinnati pest control company, brought in 2,000 customers (onequarter of their full list). An HVAC contractor is working with a list of 1,700 of its customers. Additional companies account for approximately 300 more homeowners. The process has begun to contact the homeowners and bring them into the system in various ways. The pest control company will be marketing energy upgrades to its customers through a partnership with HUB. HUB will engage them to complete an online home score. When they do that, they will be entered into the program and have full access to various HUB benefits. HUB will train the pest control home technicians to watch for signs of needed repair and report back to their company. Then HUB will contact the people on that list to convince them to have a walk-through assessment and ultimately a full-house energy audit or checkup.

During the last decade, the HVAC contractor has developed a home maintenance program. The 1,700 homeowners listed have a contract with the HVAC supplier to check and clean their system annually. This customer network, with an ongoing relationship with each homeowner, positions the HVAC contractor to watch for further upgrades. The HVAC employees are trained by the Building Performance Institute and will be able to guide the homeowners with safe choices. They will also recruit the homeowners to become HUB members, wherein they can then refer friends and family to the HUB and earn referral fees on future transactions.

HUB originally focused their recruiting efforts on companies in the home product and improvement industries that have large customer bases such as remodelers, mechanical contractors, and siding and roofing specialists. The NorthernSTAR team encouraged them to look for large, regional pest control companies. HUB began to seek referral partnerships with companies representing home service industries. They did so and entered into a relationship with the pest control company mentioned above. HUB's first business related to home services and to become a referral partner also helped it extend their business reach to the greater metropolitan area of Cincinnati. 


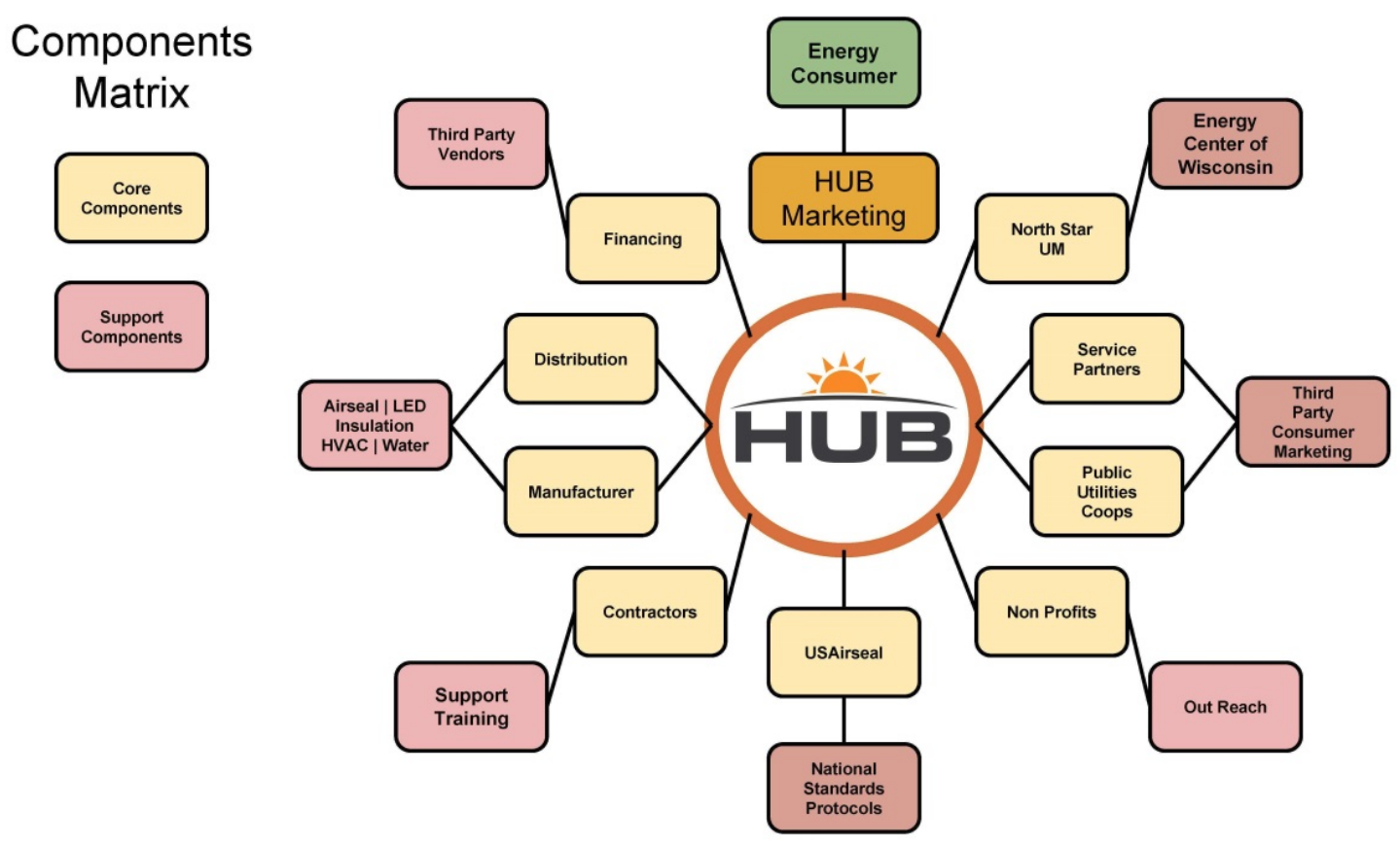

Figure 3. Graphic supplied by HUB Energy Group showing business connections to the HUB

To address scale, HUB is currently developing plans to test a program pilot in Minneapolis, Minnesota. Additional pilot tests would include cities in hot/humid and mixed-humid climates before scaling to a national model. USAirSeal would expand services and professional training to each location to provide the base for home performance assessments, air sealing insulation, and longer-term home asset management. They have also connected with Duke Energy (a local utility) and are listed as an approved contractor.

HUB recently aligned with Allied Building Products. Allied Building Products sells roofing, siding, insulation, and other building products to building contractors. It is a chain of 140 stores in 30 states. HUB will begin training store sales employees in the basics of building science protocols and product application so contractors will make better selections when improving homes. This business relationship will be a base for recruiting contractors to the HUB and to help them refer their homeowners. As this relationship grows, and with the help of the online platform, Allied can assist HUB in creating branches around the United States.

HUB is also reaching out to BA. They have strenuously pursued a relationship with NorthernSTAR as well as with the Building America Retrofit Alliance.

Finally, HUB recently engaged a manager of a large, multi-family apartment company that has 8,500 units and another that manages 127 condo associations with close to 30,000 condominiums in its portfolio. The rental property manager will join the HUB as a referral agent to learn about building science and have access to vetted contractors as they upgrade their buildings. The condo company is going to pursue help from the HUB to encourage condo owners to upgrade their 
homes. They are recruiting HUB to work with their condo associations to teach and train them about energy-efficiency and home-energy upgrades.

\subsection{Questionnaire for Home Performance Professionals}

One hundred members of the MBPA were sent an initial email with a link to an online questionnaire to gain a better understanding of their business format, revenue needs, and interest in expanding their services to homeowners through relationships with home service companies. A total of 18 members provided responses. The members that responded represent a wide variety of professions including building contractors, energy auditors and raters, consultants, trainers, government employees, program managers, researchers, and sales professionals. The types of work they perform or facilitate related to building science is represented in Figure 4.

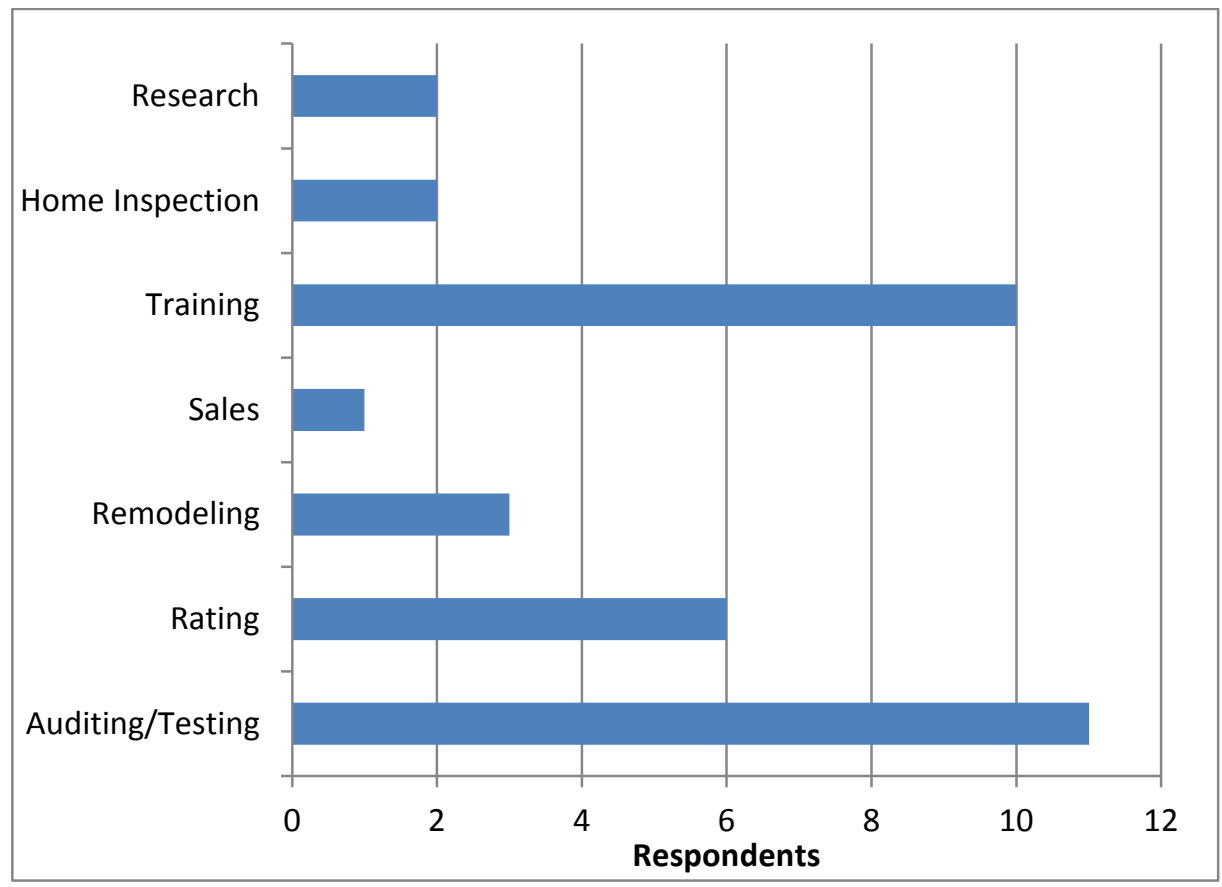

Figure 4. Types of building science work performed by MBPA members

MBPA members serve a variety of clients including homeowners, contractors, utility companies, and government entities, as show in Figure 5. 


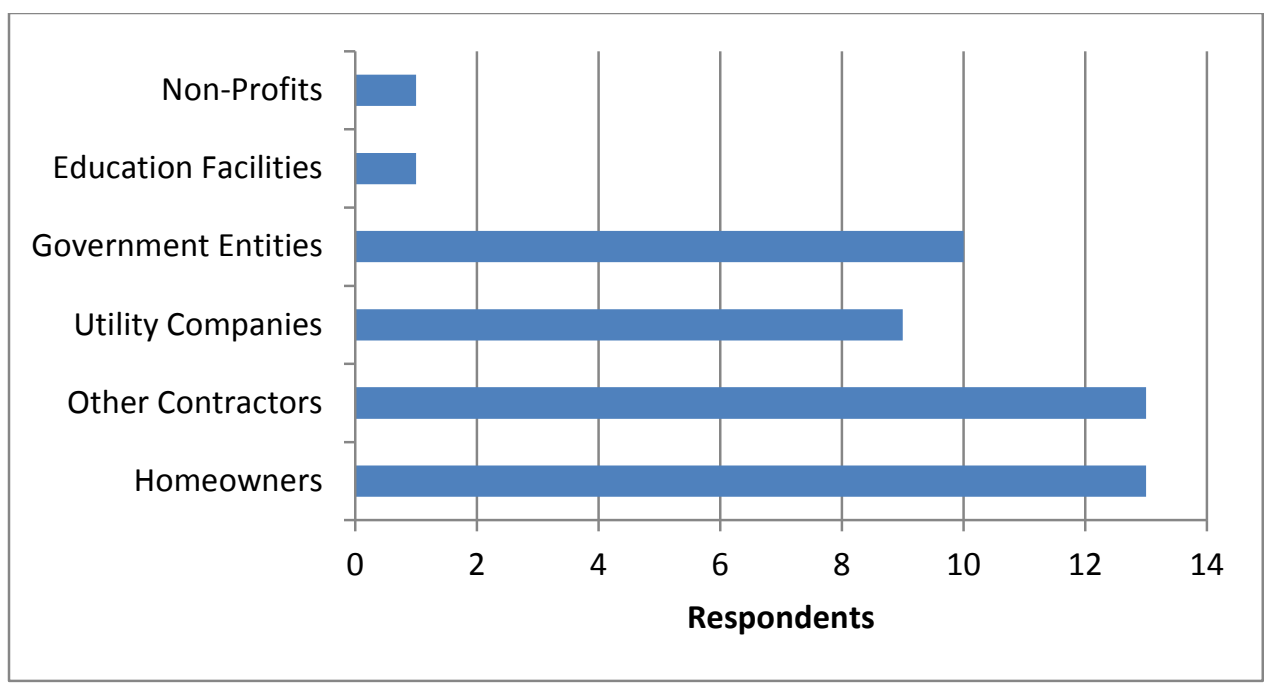

Figure 5. Clients of MBPA members

The members were introduced to the idea that leading home service companies in pest control and lawn care are already offering energy upgrades to their customers via insulation and water management. When asked about their interest in providing blower door testing or air-sealing services to these nationally-based companies, the majority would be interested in working with nationally-based companies, as shown in Figure 6.

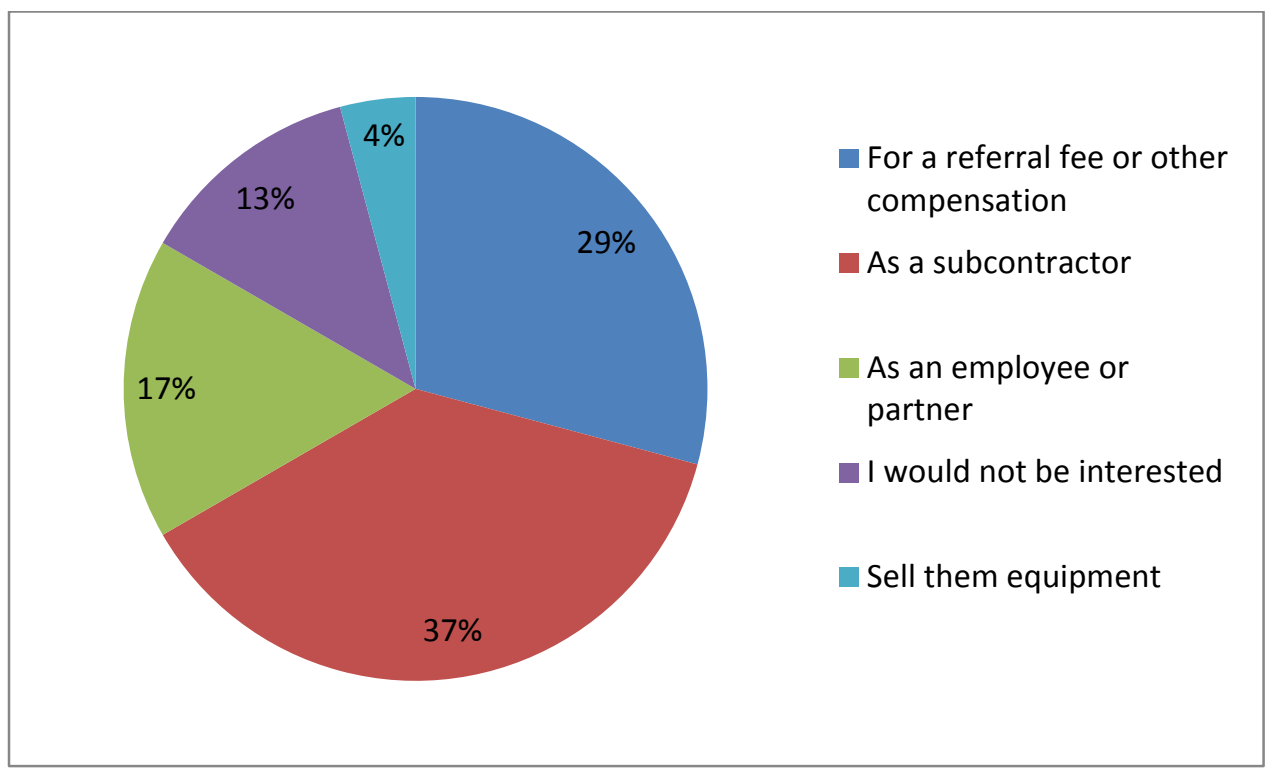

Figure 6. Member interest in working with nationally-based home service companies

When the question was changed from offering services to small, local home service companies rather than nationally-based companies, the responses were similar, but there was a slight decrease in the number of respondents that would not be interested, as shown in Figure 7. 


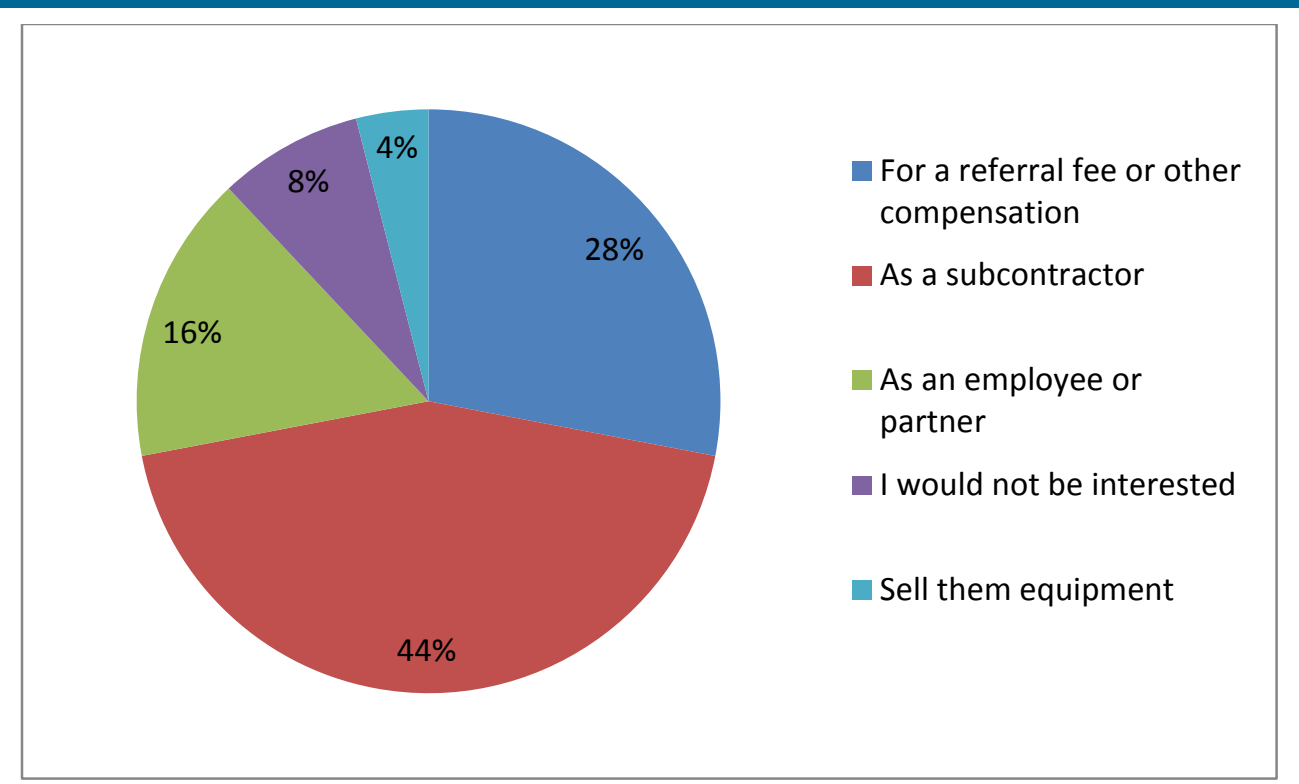

Figure 7. Member interest in working with locally-based home service companies 


\section{Results}

The literature review demonstrated the extent to which homeowners are already installing energy upgrades through their home service companies. At $\$ 11$ billion in total revenue, pest control is leading the way by offering services such as attic and wall insulation, air sealing, and water management. Some regional pest control companies also provide full-service remodeling, handyman, HVAC, electrical, and plumbing services. A few companies in the highly fragmented $\$ 73$ billion lawn care and landscape industries have entered into the energy-retrofit market as well. Insulation appears to be the primary energy upgrade. It does not appear that home security and chimney sweeping companies are actively engaged in energy upgrades.

Insulation, however, is not the primary means of connecting to a customer. Services that solve a problem - e.g., pest control, lawn care - are typically the main focus of a website. Pest control companies that offer insulation appear to market it using three key reasons:

1. New insulation is used to replace insulation infested with or damaged by pests.

2. Cellulose insulation treated with borates can help prevent future pest infestation with low toxicity.

3. Cellulose insulation improves energy efficiency.

Lawn care companies offer insulation primarily to improve comfort or reduce energy bills. Insulation is often marketed to homeowners with three performance effects: thermal, acoustical, and pest control. To many homeowners, pests are a bigger headache (pain) than energy bills, so selling pest control to alleviate the larger pain becomes an effective strategy. Carrying this strategy further, a window-washing company can help sell air-sealing and other services by applying their knowledge of the conditions they see on the windows.

Several common themes on the consumer-facing pages of pest control and lawn care websites are worth noting:

- Trustworthiness is promoted via criminal background checks of employees, well-labeled company vehicles, and uniformed employees.

- Financial incentives are offered to encourage customers to try additional services and/or to provide referrals to friends and family.

- Knowledge of industry best practices is promoted by listing the amount of training the company representatives are required to complete and the industry certifications the company has earned.

The interviews with business professionals from home service companies provided insight into the sustainable success of the home services industry. The owner of OSI mentioned that his company is first and foremost a marketing business that offers pain management. Marketing and sales drive the connection to customers for long-term engagement and trust. His success was built on offering a service (lawn care) that he could easily sell using relational sales supported by call centers and databases. Additional services were added after careful consideration of what percentage of current customers would want it, how much effort would need to go into 
generating awareness, the ease of training employees to provide quality service, and overall liability.

A review of home service websites and their outreach to professionals supports comments by the owner of OSI. Large home service companies make it apparent that their franchisees, employees, and branches are connected to the corporate network for marketing and sales support, database management, training, and technical help. A branch may be owned and operated locally, but the marketing engine that drives the continued engagement and management of long-term homeowner needs is supported by a national system.

Interviews with business professionals uncovered an additional advantage to offering energy upgrades: energy services could be installed during nonpeak times to help keep employees working year-round at regular pay.

When business motivations are combined with consumer outreach efforts, it is apparent that the success experienced by home service companies aligns with the recommendations outlined for energy-efficiency programs (Fuller et al. 2010). It is common for home service companies to:

- Sell what people want or need.

- Define an audience to target and deliver persistent messaging.

- Be a trusted messenger.

- Include incentives such as financing and rebates.

- Collect data, and measure success.

- Be available at the time of need.

The interviews with professionals, the questionnaire results from the MBPA members, and the literature review all illustrated the understanding that referrals are an important means for generating revenue and new clients. The number of referrals can grow exponentially when several market networks connect or cooperate together. Many companies offer incentives to satisfied customers to refer their businesses to others. A formal referral relationship among companies is desired, but it is not a common practice. Small companies face hurdles of allocating time and resources to developing and maintaining business-referral relationships.

HUB's market-delivery concept combined with the energy audits and air sealing supplied by USAirSeal uses a referral-based networking and lead-generation system to raise awareness and inspire building science-guided upgrades. The referral network, supported through an advanced data-organizing platform known as HUB2e, connects homeowners to prescreened, trained professionals enrolled in HUB's trade contractor network to improve the ease of finding and hiring contractors. HUB2e also serves as the tracking system to help homeowners manage the upgrades in their homes throughout time to increase opportunities for right-ordered improvements. 


\section{Conclusions}

Approximately 80 million to 100 million homeowners in the United States will need or desire upgrades to their homes throughout time. Very little evidence in the $\$ 400$ billion home improvement industry shows that sound building science-guided upgrades are completed at a significant level. Even within the BA research, there is great difficulty integrating research and tested measures in homes. It is possible that the obvious home improvement supply chain is insufficient and not connecting all links. This obvious supply chain expects that the customer (homeowner) will self-engage in the marketplace to find the home improvement products and services that they require. The findings indicate that the large-scale deployment of good research in existing homes will require additional pathways and methods delivered directly to the customer. This means engaging homeowners directly in trusting relationships during a long time frame. The fastest way to accomplish this would require turning to industries that have already built numerous homeowner relationships and creating synergistic approaches with them.

One group of potential partners, one that is not obviously recognized as an aspect of the home improvement supply chain, has moved forward by selling insulation and air sealing; companies within the home services industry, primarily pest control and lawn care, are promoting energy upgrades.

This study focuses on the home services industry because of the large total revenues individual market sectors experience each year by solving home problems and selling services to homeowners. These businesses know how to market and sell face-to-face and have established customer-based networks to which they return for repeat visits. Hence, not only does the home services industry have massive networks and built-in sales forces, but it has learned that it can solve other problems in addition to the original focuses of their services.

BA has always worked effectively for research with industry partners, product manufacturers, and builders of new construction. The real customer in the $\$ 175$ billion new home construction market is essentially the builder, and this approach was a good fit for BA. With existing homes, however, the customer changes to the homeowner. This change dramatically affects how BA operates, behaves, and connects. The most significant change is that the buyer of new construction purchases all new energy technology (upgrades) up front and all at once. In existing homes, upgrades are made by homeowners incrementally during a long period of time.

The first part of the solution is to find partners that are very effective at providing long-term services to homeowners. The second part of this transaction is finding a person or entity that can facilitate and merge building science-based expertise with sales and marketing to help these partners integrate energy-efficiency upgrades into their portfolios. Because most home service companies do not have building performance expertise in-house, it will be difficult for them to move into this role with their current employees. Large organizations may be able to expand inhouse services with guidance from BA to ensure safety and achieve maximum energy savings. Smaller home service companies not able to offer technical expertise from within could offer upgrades through a well-organized building performance-based third party.

1. Is it feasible to use the home services industry to deliver building science-guided home performance upgrades? 
This study cited examples that show that it is feasible that businesses in the home services industry can deliver or partner to deliver building science-guided performance upgrades. The most probable business type for this is the pest control sector. It is clear that many home service companies have realized that with their large direct sales capacity they can grow revenue by offering new services to existing customers. Several large companies have ventured into thermal and pest insulation with boric acid for pest control. Others have included air sealing and water management. These companies advertise that they support best-practice pest control solutions, but it is possible that they do not follow building science approaches when air sealing and adding attic insulation. The research team believes that it is critical to establish a connection with home performance experts by either hiring internally or third-party partners or subcontractors.

It is not clear from the literature review whether the energy upgrades offered by home service companies are currently guided by building science and accurately address the needs of individual houses. Except for one small lawn care company that provides energy audits and insulation, there was no mention of any of the national companies conducting a test-in/test-out process to ensure combustion safety or proper ventilation for mechanical equipment and occupants. It is also not clear if the major home service companies would be interested in offering energy solutions beyond the typical upgrades already in the market. Several attempts to contact Orkin and TruGreen were met with no response. It is possible that the lack of guidance and testing by these companies is causing health hazards for the occupants and long-term performance problems for the houses.

It is also encouraged that home service companies be recognized by the building science community as home improvement contractors. High-level leadership (e.g., by DOE or the U.S. Environmental Protection Agency) could be assisting large revenue pest control and lawn care companies in much the same way that they partner with production builders to advance best practices. The revenue capacity and established sales capabilities of these companies provide extensive opportunities for large-scale applications upgrades. To ensure that these upgrades are scaled safely and appropriately to the needs of a house, BA expertise can facilitate relationships among home service providers and home performance professionals.

In smaller, localized companies, a different mechanism is needed to connect home service providers to the home performance industry. Many small companies do not have the internal capacity to engage business synergies and rely instead on homeowner referrals for growth.

2. What company characteristics would most likely facilitate the successful integration of building science-guided upgrades into an existing portfolio of home services?

Five common characteristics of home service companies support the idea that a business framework and philosophy exists within the industry to advance building science-guided services:

- Financial success and business sustainability has been established by providing dependable service and developing trust before introducing new services. This is important for helping homeowners build confidence in the ability of the provider to be dependable with the new service. 
- Many companies promote their success in pest control as a product of creating customized solutions. This would be a critical component for the success of whole-house energy retrofits.

- Long-term engagement and communication strategies have enabled pest control companies to maintain relationships with homeowners for extended periods of time. This is important for being the trusted entity when an energy-related repair or replacement is needed.

- Leaders in the home services industry have extensive sales and marketing programs supported by database networks and call centers that help raise awareness of new product offerings and encourage homeowner engagement. This is important for getting homeowners to make upgrades to their homes and to track those upgrades over time.

- Established training programs help advance the success of new technicians as well as help established employees integrate new services into their protocol. This is important for communicating building science best practices to professionals.

3. What opportunities exist through referral networks to advance home performance upgrades?

The interviews with professionals, the questionnaire results from the MBPA members, and the literature review all illustrated the understanding that referrals are an important means for generating revenue and new clients. Many companies offer incentives to satisfied customers to refer their business to other homeowners. A formal referral relationship among companies is intriguing or desired, but it is not a common practice. Small companies face hurdles of allocating time and resources to developing and maintaining formal business referral relationships.

The HUB Energy Group has developed a well thought out model that can potentially engage homeowners, recruit and qualify contractors and product suppliers, and provide building science guidance and education at all levels. Software was developed to manage and track all levels. The HUB market-delivery model was conceived as an incentive-based, referral networking and leadgeneration system to raise awareness and inspire homeowners to take action to improve the energy efficiency, safety, and durability of their homes. It was designed to benefit both professionals and homeowners by connecting homeowners to prescreened, trained professionals enrolled in the HUB trade contractor network to improve the ease of hiring contractors. HUB is currently conducting a pilot test in Ohio and has plans to study a second market in Minneapolis, Minnesota. 
4. What could be the expected scale and speed of moving this synergy into place?

The marketing and communications process used by home service companies offers a key avenue to rapidly raise awareness for and the value of building science-guided upgrades. Trust built among home service providers and homeowners through repeated face-toface contact has already been proven as a catalyst for action. Several large home service companies such as Orkin, Terminix, and TruGreen are marketing insulation, air sealing, and radiant barriers as comfort and energy savings strategies alongside their pest control strategies, and this indicates that energy upgrades have revenue value. However, the team did not uncover specific information to quantify the current value to estimate the scale for individual upgrades.

The energy savings attained through the installation of insulation or air sealing would not alone meet the BA goals of $40 \%$ energy savings by 2030 . More upgrades would need to accumulate throughout time to achieve this goal. Companies in the home services sector would need to sell homeowners additional energy upgrades (e.g., mechanical equipment, foundation or wall insulation) to increase energy savings. They would also have to focus on building scienceguided upgrades (either internally or through external partnerships) for BA to meet the building durability and occupant health and safety goals for 2030 .

Although large organizations might approach this through specialized home performance employees and departments that are managed from within, smaller home service companies may not be in a position to do so. The key solution needed

\section{Comments from Susanne Shelton}

This concept made a lot of sense recently to national marketing expert Susanne Shelton. After

participating in a panel discussion sponsored by the HUB Energy Group at the Wisconsin Better

Buildings: Better Business conference, where she heard a summary of our research, she wrote:

[The University of Minnesota,] like many of us, has been trying to crack the nut on how to actually motivate homeowners to upgrade the efficiency of their homes-and do it in a way that's grounded in building science. While simply talking with people in his own circle, he began to hear anecdotes from friends in the home services industry-pest control, lawn care, home cleaning, etc.-about their workers being asked if they could help with a home improvement issue. ...

Folks in the home services business have established a level of trust (or at least familiarity) with homeowners because they show up regularly and do a good job.

They're around at the "point of pain." Tom (from University) makes an excellent point that people truly only want to make efficiency improvements when they're in pain-an ice dam has developed on the edge of the roof, the HVAC system is on the fritz, mold has appeared somewhere in the house, a room has become uncomfortable. Because the pest control guy or lawn care guy is around regularly, he gets asked if he knows how to fix this stuff. Homeowners don't know who else to ask. They've never interacted with an insulation guy or a home performance specialist. They may not even know there is such a thing as a "home performance specialist," so they truly have no idea who to call for help. It's simply easier to ask the guy who's right there.

You've heard me expound often about the real drivers and barriers for energy efficiency and sustainability. For years in our Eco Pulse research we've asked, "If you had to choose between your comfort, your convenience, or the environment, which would you choose?" Though we've seen movement recently towards the environment, when you look at the trend you'll see that we are creatures of comfort and convenience. One of the reasons we don't buy greener products or make efficient upgrades to our homes is that it's inconvenient. And the greater the perceived inconvenience, the greater the resistance to doing it.

So it makes perfect sense that at the time of pain-when the emergency now outweighs the convenience factor-people will ask the folks right in front of them. The lesson here? If you're trying to sell any kind of green or efficient home improvement to homeowners, consider partnering with companies in the home services industry. They have the trust, an established marketing and sales channel, and they're in the right place at the right time. Selling efficient lighting or insulation through a bug guy may seem unlikely, but it looks like it'll work. Like gangbusters (Shelton 2015). 
to impact large-scale energy upgrades in existing homes at the localized level is to support a building science-based intermediary that will develop a working model such as that proposed by HUB. HUB's model has management, sales, and an effective information system in place. It could be the catalyst for rapid change not only through the engagement of many small companies but also via collaboration with large home service companies. HUB's role as connector and home asset manager relieves home service companies from having to be the provider of all energy upgrades. Instead, they would be one cog in the wheel overseen by HUB, which would connect all the parts of the system. HUB would benefit from the communications and awarenessbuilding capabilities of the home services company. HUB would be responsible for guiding new customers down the path of appropriate, building science-guided upgrades, and they would manage the care of the home throughout time.

It is possible that there are millions of homeowner customers now in various customer databases that could be gathered into one system so that they could be informed and encouraged to install upgrades when moments of "pain" arise.

\subsection{Next Steps}

Home service companies are already engaged with homeowners and use their earned trust to offer services including energy upgrades that are desired by consumers and generate revenue. Pest control is the industry sector leading the way in offering energy upgrades. A focused research effort to create synergy among pest control companies and home performance providers is recommended as a next step. National and regional pest control companies should be engaged by building science industry leaders such as DOE or the U.S. Environmental Protection Agency, which have extensive experience working with large industry partners. Contact and partnering at this level could be more successful.

The NorthernSTAR team proposes further investigation into the HUB referral management program with its emphasis on building science. HUB's newly developed database management software platform offers a promising avenue for managing referral systems, lead generation, and long-term, whole-house upgrades that have building science oversight. More investigation is needed to understand the extent and method to which HUB can influence local markets, scale to a national presence, and connect with home service companies. Also, we can include an additional evaluation of HUB's market approach and acceptance.

Gathering additional data from HUB will provide further information about the following:

- Home profile data

- Pre- and post-energy assessment details

- Types of upgrades as well as how well they follow building science protocols and best practices

- Homeowner decision-making processes, including why or why not an energy-upgrade transaction was made and whether they were "in pain" or if there were other motives

- Upgrade outcome follow-up, including what worked well and what failed. 
Other potential studies that are needed include a broader national survey of home performance professionals and exploring opportunities with home inspection companies and warranties during the real estate transaction process. 


\section{References}

ABC. 2014. “ABC Home \& Commercial Services.” Accessed August 22, 2014. http://www.abchomeandcommercial.com/austin/.

Advance. 2015. Accessed March 1, 2015. http://advancepest.com/insulationservices.html.

Arrow. 2014. "Specialized Home Services.” Accessed March 15, 2015.

http://www.arrowexterminators.com/home-services/.

BA. 2015. "Building America Program Draft Technology-to-Market Roadmaps." Washington, D.C.: U.S. Department of Energy Building America Program. Accessed April 7, 2015. file://C:/Users/Cindy/Downloads/Build_America_Research-to-Market_Plan_Roadmaps.pdf.

Casey, S., and C. Booten. 2011. Energy Savings Measure Packages: Existing Homes. Golden, CO: National Renewable Energy Laboratory. Accessed March 27, 2015.

http://apps1.eere.energy.gov/buildings/publications/pdfs/building_america/energy_savings_meas ures.pdf.

Chimney Safety Institute of America. 2012. Chimney Service Industry 2012 Survey Findings. Plainfield, IN: National Chimney Sweep Guild and the Chimney Safety Institute of America. Accessed December 8, 2014. http://www.csia.org/aboutcsia/industry survey results \%282012\%29.aspx.

EagleMac. 2015. "Market Analysis.” Accessed May 2, 2015.

http://www.eaglemac.us/strategy/market-analysis/.

Ehrlich. 2014. “Integrated Pest Management.” Accessed March 25, 2015. http://www.jcehrlich.com/integrated-pest-management/.

Elite Energy Solutions. 2015. Accessed March 25, 2015. http://www.eliteenergysolutions.com/contact.html.

Fuller, M., C. Kunkel, M. Zimring, I. Hoffman, K. Soroye, and C. Goldman. 2010. Driving Demand for Home Energy Improvements. Berkeley, CA: Lawrence Berkley National Laboratory. Accessed March 5, 2014. http://emp.lbl.gov/sites/all/files/REPORT\%2010w\%20res\%20bnl-3960e.pdf.

Guardian Pest Solutions. 2014. Accessed July 20, 2014. http://guardian-online.com/residential/.

Huelman, P. 2014. "The Remodeling Conundrum: When the Order Matters." Cityscape: A Journal of Policy Development and Research 16(3): 153. U.S. Department of Housing and Urban Development. Accessed March 1, 2015. http://www.huduser.org/portal/periodicals/cityscpe/vol16num3/ch8.pdf.

IBISWorld. 2015. Landscaping Services in the US: Market Research Report. New York, NY. Accessed March 30, 2015. http://www.ibisworld.com/industry/default.aspx?indid=1497. 
Lake Norman Pest Control Company. 2015. Accessed March 16, 2015. http://lakenormanpest.com/.

Lawn \& Landscape. 2013. "By the Numbers.” October 4. Accessed July 20, 2014. http://www.lawnandlandscape.com/111013-state-industry-data.aspx.

Magic Pest Control. 2015. Accessed April 2, 2015. http://www.magicpest.com/arizonapests/scorpions/.

Neme, C., M. Gottstein, and B. Hamilton. 2011. Residential Efficiency Retrofits: A Roadmap for the Future. Montpelier, VT: The Regulatory Assistance Project. Accessed March 5, 2014: www.raponline.org/document/download/id/918.

Newport Partners, LLC. 2010. Report: Motivating Home Energy Improvements: Focus Groups for the U.S. Department of Energy. Davidson, MD. Accessed January 5, 2015. http://energy.gov/sites/prod/files/2013/11/f5/doe fg_report.pdf .

Orkin. 2014. Accessed March 15, 2015. http://www.orkinservices.com/.

Orkin. 2015. "Franchise Opportunities.” Accessed March 15, 2015. http://www.orkin.com/franchise/.

Palmer, K., M. Walls, H. Gordon, and T. Gerarden. 2011. Assessing the Energy-Efficiency Information Gap: Results from a Survey of Home Energy Auditors. Washington, D.C.: Resources for the Future. Accessed March 15, 2015. http://www.rff.org/rff/Documents/RFF-DP-11-42.pdf.

Scarborough. 2013. "New Homeowners Injected \$19 Billion into the Home Improvement Retail Market During the Past Year." Dialog Blog, April 17. Accessed May 7, 2015. http://dialog.scarborough.com/index.php/new-homeowners-injected-19-billion-into-the-homeimprovement-retail-market-during-the-past-year/.

Security Sales and Integration. 2014. "Installation Business Report Overview." In Security Sales \& Integration: The Gold Book 2014. Golden, CO: Allegion. Accessed March 28, 2015. http://securitysales.epubxp.com/i/223614-goldbook-2014/5.

Shelton, S. 2015. "Meet Your New Sales Guy: The Local Bug Man.” Shelton Group Blog, March 12. Accessed May 2, 2015. http://sheltongrp.com/meet-your-new-sales-guy-the-localbug-man.

Steinau, R. 2011. "Women in Pest Control." Ask the Exterminator Blog. Accessed December 7, 2014.

http://www.asktheexterminator.com/Miscellaneous/Women_In_Pest_Control_printer.shtml.

Stout, H. 2015. "Amazon, Google and More Are Drawn to Home Services Market." The New York Times, April 12. Accessed April 20, 2015. http://www.nytimes.com/2015/04/13/technology/amazon-google-and-more-are-drawn-to-homeservices-market.html? $\mathrm{r}=0$. 
Terminix. 2015. Accessed March 15, 2015. http://www.terminix.com/additional-pestsolutions/attic-insulation/.

TruGreen. 2015. Accessed March 15, 2015. http://www.trugreen.com/products-andservices/insulation-services/.

U.S. Energy Information Administration. 2009. "Residential Energy Consumption Survey, Table HC2.4: Structural and Geographic Characteristics of U.S. Homes by Number of Household Members." Accessed March 15, 2014.

http://www.eia.gov/consumption/residential/data/2009/\#undefined.

Univar. 2014. PCT Top 100 Commemorative Poster. Univar; St. Paul, MN 2015. http://www.pctonline.com/FileUploads/file/PCT2014Top100Poster2.pdf. Accessed March 15, 2015.

Western Pest Services. 2015. Accessed March 15, 2015. http://www.westernpest.com/. 


\section{Appendix A: Online Questionnaire for Minnesota Building Performance Association Members}

\section{Q1. What is your primary occupation?}

Q2. What type of work do you perform or facilitate related to residential building science? Check all that apply.

_ Auditing/testing

Rater

Remodeler/contractor

Sales

— Trainer/educator

_ Architect/designer

Home inspector

Code official

- I do not perform work related to residential building science.

_ Other (Please specify.)

Q3. Who are your customers? Check all that apply.
Homeowners
Other contractors
Utility companies
Government entities
_ Other (Please specify.)

Q4. Please describe your customer base:

I have more leads than I can handle.

I have sufficient leads.

_ I need to find ways to increase my leads.

_ Other (Please specify.)

Q5. What types of marketing strategies do you use to generate leads? Check all that apply.

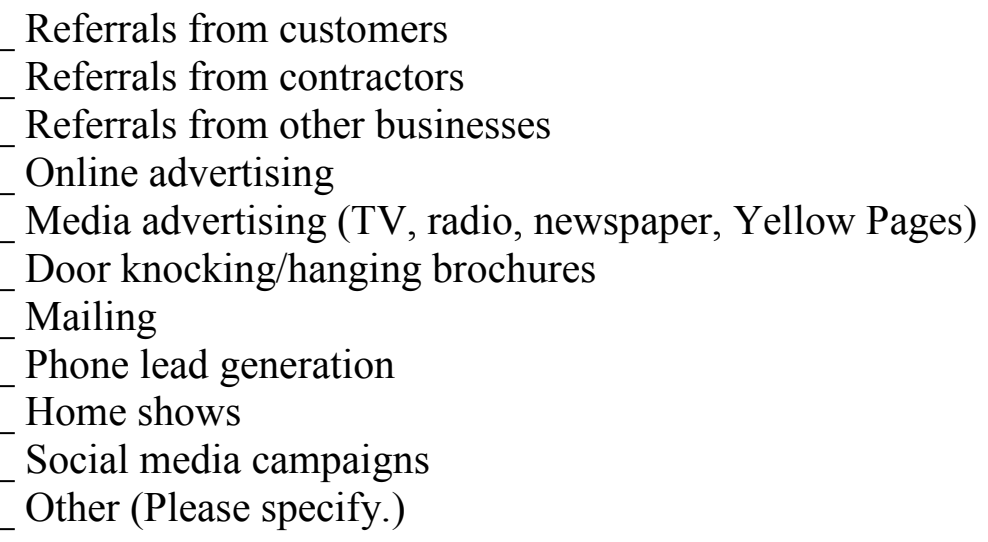


Q6. Are you willing to pay a fee for leads that result in a business transaction?

Yes
- No

Q7. A simple Internet study shows that Terminex and Orkin (pest control) and TruGreen (lawn care) each generate more than a billion dollars in yearly revenue. These home service companies, along with many others nationwide, are now developing and selling their own insulation products. Some are also adding air sealing and energy audits to their product lines. Some of this work is being done from inside these companies, and some is done with external partners.

Our best estimate at this time is that $60 \%$ of the 89 million homes in the United States are receiving services by a home services company (e.g., pest control, lawn care, window washing, and home security). Many homes are receiving services multiple times per year. Many home service providers have phone lead-generation systems and are continually in contact with homeowners before, during, and after delivering a service. The result of this is the existence of very large and sophisticated marketing networks of customers who are already accustomed to home service providers.

As a national lawn care company, TruGreen also offers insulation services. If TruGreen, or a large home services company like TruGreen, wanted to partner with home performance professionals to add blower door testing and provide air sealing, would you be interested in working with them? Check all that apply.

For a referral fee or other compensation

As a subcontractor

As an employee or partner in the business

I would not be interested in working with a home services company.

_ Other (Please specify.)

Q8. If a small, local home service provider (e.g., pest control, lawn care, home security, window washing) was looking to add to their business by providing some performance upgrade products, how would you work with them? (A small company may have 4,000 to 10,000 repeat customers.) Check all that apply.

For a referral fee or other compensation

As a subcontractor

As an employee or partner in the business

I would not be interested in working with a home services company. Other (please specify) 
Q9. If you were to consider working with a home services provider, what role would you perform?

Referral agent

Partner

Subcontractor

I would not be interested in working with a home services provider.

Other (Please specify.) 


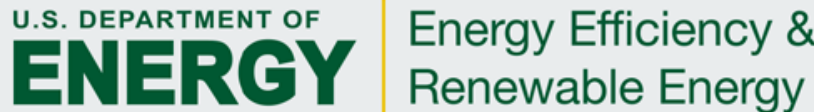

